\title{
Serum and follicular fluid concentrations of polybrominated diphenyl ethers and in-vitro fertilization outcome
}

\section{Citation}

Johnson, Paula I., Larisa Altshul, Daniel W. Cramer, Stacey A. Missmer, Russ Hauser, and John D. Meeker. 2012. "Serum and Follicular Fluid Concentrations of Polybrominated Diphenyl Ethers and in-Vitro Fertilization Outcome." Environment International 45 (September): 9-14. doi:10.1016/j.envint.2012.04.004.

\section{Published Version}

doi:10.1016/j.envint.2012.04.004

\section{Permanent link}

http://nrs.harvard.edu/urn-3:HUL.InstRepos:27332625

\section{Terms of Use}

This article was downloaded from Harvard University's DASH repository, and is made available under the terms and conditions applicable to Other Posted Material, as set forth at http:// nrs.harvard.edu/urn-3:HUL.InstRepos:dash.current.terms-of-use\#LAA

\section{Share Your Story}

The Harvard community has made this article openly available.

Please share how this access benefits you. Submit a story.

Accessibility 


\title{
Serum and follicular fluid concentrations of polybrominated diphenyl ethers and in-vitro fertilization outcome
}

\author{
Paula I. Johnson ${ }^{a}$, Larisa Altshul ${ }^{b, c}$, Daniel W. Cramer ${ }^{d}$, Stacey A. Missmer ${ }^{d}$, Russ Hauser ${ }^{b}$, \\ and John D. Meeker ${ }^{a,}{ }^{*}$ \\ aDepartment of Environmental Health Sciences, University of Michigan, 1415 Washington \\ Heights, Ann Arbor, MI 48109 USA \\ bepartment of Environmental Health, Harvard School of Public Health, 677 Huntington Ave., \\ Boston, MA 02115 USA \\ 'Environmental Health and Engineering, Inc., 117 Fourth Avenue, Needham, MA 02494 USA \\ dObstetrics, Gynecology and Reproductive Biology, Brigham and Women's Hospital, 75 Francis \\ St., Boston, MA 02115 USA
}

\begin{abstract}
There is evidence of endocrine disruption and reproductive effects in animals following exposure to certain PBDEs, but human studies are limited. The goal of this study was to investigate the use of serum and follicular fluid as biomarkers of exposure to PBDEs and to explore whether a relationship between PBDE exposure and early pregnancy loss exists. We measured 8 PBDE congeners in archived serum and ovarian follicular fluid samples from 65 women undergoing invitro fertilization (IVF). Logistic regression models were used to predict the odds of failed embryo implantation associated with higher levels of PBDEs among the women in the study. There were moderate Kendall's Tau-beta correlations between serum and follicular fluid concentrations of BDE 28, 47, 100 and $154\left(\mathrm{~T}_{\beta}=0.29-0.38\right.$, all $\mathrm{p}$-values $\left.<0.005\right)$, but BDE 99 and 153 were not correlated between the two matrices $\left(\mathrm{T}_{\beta}<0.2\right.$, $\mathrm{p}$-values $\left.>0.05\right)$. Women with detectable concentrations of BDE 153 (39\% had detectable levels) in follicular fluid had elevated odds of failed implantation compared with women who had non-detectable concentrations (adjusted $\mathrm{OR}=10.0$; $95 \% \mathrm{CI}: 1.9$ to $52 ; \mathrm{p}=0.006$; adjusted by age and body mass index). These findings suggest that exposure to BDE 153 may be associated with failed embryo implantation. Due to our observation of only moderate correlations between matrices, serum PBDE concentrations may not be a good indicator of follicular fluid concentrations when studying early pregnancy endpoints in women undergoing IVF.
\end{abstract}

\section{Keywords}

flame retardants; PBDEs; human exposure; endocrine disruption; biomarkers; implantation; pregnancy loss; infertility

\footnotetext{
(C) 2012 Elsevier Ltd. All rights reserved.

*Corresponding author. Tel.: 734-764-7184; fax: 734-763-8095, meekerj@umich.edu.
}

Publisher's Disclaimer: This is a PDF file of an unedited manuscript that has been accepted for publication. As a service to our customers we are providing this early version of the manuscript. The manuscript will undergo copyediting, typesetting, and review of the resulting proof before it is published in its final citable form. Please note that during the production process errors may be discovered which could affect the content, and all legal disclaimers that apply to the journal pertain. 


\section{Introduction}

Polybrominated diphenyl ethers (PBDEs) are a group of flame retardants used in the manufacture of a variety of consumer products, including home electronics, upholstered furniture, carpeting, and other items containing polyurethane foam or plastics. Flame retardants are added to these products with the intention to slow the rate of burning in case of fire and meet fire safety standards such as Technical Bulletin 117 which requires that certain articles do not ignite when exposed to 12 seconds of open flame (CA Dept. of Consumer Affairs, 2000). PBDEs are not chemically bound, and thus may leach out or physically degrade and end up in indoor air and house dust. PBDEs have been measured in the indoor environment (Sjodin et al., 2008a; Stapleton et al., 2005), and house dust is expected to be a primary exposure pathway (Johnson et al., 2010; Johnson-Restrepo and Kannan, 2009; Lorber, 2008; Wu et al., 2007). Human exposure to PBDEs is widespread and body burdens in North Americans are orders of magnitude higher (around $35 \mathrm{ng} / \mathrm{g}$ lipid) than those in European countries where most PBDEs have been banned (Hites, 2004; Sjodin et al., 2008b).

Three commercial formulations of PBDEs have been produced, designated as penta-, octa-, and deca-BDE. These formulations consist of mixtures of specific PBDE congeners, and are named according to their degree of bromination. Penta- and octa-BDEs have been banned in Europe and phased out of production in the United States, and deca-BDE will begin phasing out in 2012 (EPA, 2009). Although environmental levels of some PBDEs may be declining in response to the phase-outs, the general population continues to be exposed to all of these compounds due to their persistence and continued release from older products.

PBDEs have been shown to alter reproductive and thyroid hormone homeostasis in animal studies. Exposure to pentaBDE commercial mixtures decreased levels of thyroxine (T4) in rodent studies, possibly by inducing hepatic enzymes that increase thyroid hormone clearance (Ellis-Hutchings et al., 2006; Fowles et al., 1994; Hallgren et al., 2001; Skarman et al., 2005; Stoker et al., 2004; Zhou et al., 2001, 2002). Some studies, using low doses ( $\mu \mathrm{g} /$ $\mathrm{kg}$ ) that result in tissue concentrations comparable to human body burdens, also show effects of pentaBDE exposure on T4 levels (Kuriyama et al., 2007; Blake et al., 2011). Although Zhou et al. (2002) found decreased T4 levels and increased liver weights and hepatic enzyme activity in dams and fetuses in response to gestational pentaBDE exposure, maternal weight gain, litter size and sex ratio, and offspring viability or growth were not significantly affected. Zhou et al. (2001) also tested a decaBDE mixture and did not observe effects on thyroid hormones, liver weights or hepatic activity. However, other studies have observed decreases in serum T4 levels in rodents exposed to decaBDE (Rice et al., 2007; Kim et al., 2009). The mechanism of thyroid hormone disruption in rodents may differ from humans because of differences in thyroid hormone transport proteins. Transthyretin is the major transport protein for T4 in rodents. While humans also utilize transthyretin, it is thyroxinebinding globulin that is the major protein binding T4 in humans, which has a much higher affinity for T4 than transthyretin. Studies of the reproductive system have revealed effects in both male and female rats after exposure to PBDEs. For instance, Talsness et al. (2008) found that gestational exposure to BDE 47 decreased circulating levels of estradiol and the number of ovarian follicles in offspring. Lilienthal et al. (2006) reported effects on the number of ovarian follicles resulting from exposure to BDE 99. A recent in-vitro study suggested that PBDEs may disrupt ovulation by stimulating progesterone secretion by ovarian follicles (Karpeta et al., 2010). Talsness et al. (2005) found that a single dose gestational exposure to BDE 99 resulted in structural abnormalities of ovaries, but no change in the number of ovarian follicles, and greater fetal resorption rates among female offspring. The higher dose resulted in a higher resorption rate than the lower dose, but the differences in resorption rates between exposure groups were not statistically significant. On 
the other hand, Hardy et al. (2002) did not find differences in rates of pregnancy or uterine implantation in rats after 20 days of gestational exposure (no observed effect level (NOEL) of $1000 \mathrm{mg} / \mathrm{kg} /$ day) to a decaBDE mixture.

Studies of potential human health effects of PBDEs are limited. A few human studies have reported associations between PBDE exposure and altered levels of the thyroid hormones thyroxine (T4), triiodothyronine (T3) or thyroid stimulating hormone (TSH) (Bloom et al., 2008; Chevrier et al., 2010; Dallaire et al., 2009; Hagmar et al., 2001; Turyk et al., 2008; Wang et al., 2010; Yuan et al., 2008). Thyroid hormone homeostasis is important for regular ovulation, fertilization and maintaining pregnancy (Cramer et al., 2003; Krassas et al., 2010; Zoeller and Meeker, 2010). We recently reported that concentrations of BDE 47, 99 and 100 in house dust were associated with increased levels of serum T4 in 24 men (Meeker et al., 2009a). PBDEs in house dust were also inversely associated with luteinizing hormone and follicle stimulating hormone in these men. Human studies involving PBDE exposure and female reproductive function are even more limited, but two studies suggest PBDEs may adversely impact fertility. Chao et al. (2007) found evidence of shorter menstrual cycle length in relation to elevated levels of PBDEs in breast milk, although this association was not statistically significant in their small sample size. Harley et al. (2010) recently reported significantly reduced fecundability, in terms of time to pregnancy, associated with elevated serum levels of PBDEs in a group of Californian women.

Assisted reproduction technologies such as in-vitro fertilization (IVF) provide the opportunity to study stages of reproduction that are otherwise not observable in the general population, such as oocyte quality, fertilization, embryo quality, and implantation. In addition, biomarkers of environmental exposures, such as PBDEs, may be measured in follicular fluid that is usually collected during IVF and discarded. Follicular fluid surrounds the preovulatory oocyte and provides an important microenvironment in which the oocyte develops. Depending on the health endpoint of interest and biological mechanisms involved, the concentration of PBDEs in follicular fluid may be a more biologically relevant measure of exposure to the oocyte than serum. However, serum is the most common matrix in which to measure PBDE concentrations, and it remains unknown if serum PBDE concentrations serve as an adequate estimate of concentrations closer to the target tissue in the case of female reproduction.

In the present study, we measured PBDEs in archived serum and follicular fluid samples from 65 women who participated in a large study of predictors of in-vitro fertilization (IVF) success, where we found that PCBs and cigarette smoking were associated with IVF implantation success rates (Meeker et al., 2007a, 2011). The objective was to first attempt to quantify PBDE concentrations in follicular fluid, which to our knowledge has not been done previously, then investigate the use of serum as a biomarker of exposure to PBDEs as compared to the potentially more biologically relevant biomarker of follicular fluid (in the case of IVF outcomes). Finally, we conducted an exploratory analysis to investigate the relationship between PBDE exposure and failed embryo implantation. Failed implantation was chosen as the outcome to explore because we had a limited sample size and it is the most common point of failure in IVF cycles.

\section{Methods}

\subsection{Study population}

The main study, within which the present sub-study took place, was conducted in two funding phases (1994 - 1998 and 1999 - 2003), and details have been previously described (Meeker et al., 2007a, 2007b). Briefly, women undergoing IVF or intracytoplasmic sperm injection (ICSI) were recruited through three clinics in the Boston area to participate in a 
study of IVF outcome predictors. Women requiring either donor oocytes or donor semen were excluded. Study protocols were approved by the Human Research Committees at Brigham and Women's Hospital, Harvard School of Public Health, and the University of Michigan. Approximately $65 \%$ of those approached agreed to participate in the study.

\subsection{Serum and follicular fluid collection}

Serum samples were collected within 36 hours of each IVF/ICSI cycle, during the follicular phase immediately prior to human chorionic gonadotropin (HCG) administration. The samples were separated by centrifugation for 5 minutes, aliquoted and stored at $-80 \mathrm{C}$ until analysis. Oocyte retrieval was performed approximately 36 hours after HCG administration. The follicular fluid was obtained from the largest follicle visualized by ultrasound, and each sample consisted of fluid from only one follicle. After the oocytes were removed, the follicular fluid was centrifuged for 15 minutes, and the supernatant was placed into a clean storage tube, aliquoted and stored at $-80 \mathrm{C}$ until analysis.

\subsection{Measurement of PBDEs}

Paired serum and follicular fluid samples (from the two study phases spanning 1994 - 2003) from a total of 65 randomly selected women within the larger study were analyzed for PBDEs in 2009 by the Organic Chemistry Analytical Laboratory, Harvard School of Public Health (Boston, MA). The samples underwent liquid-liquid extraction and silica-gel column chromatography clean up, and the extracts were analyzed by gas chromatography-mass spectrometry (GC-MS) operated in negative chemical ionization (NCI) mode. Final concentrations were reported after subtracting the concentrations of the analyte measured in the procedural blank associated with the analytic batch. Target analytes were PBDE congeners 28, 47, 99, 100, 153, 154, 183 and 209. Method detection limits (MDL) were determined as three times the standard deviation obtained from the measurement of eight aliquots of bovine serum fortified with target PBDE congeners (spiked at $0.05 \mathrm{ng} / \mathrm{g}$ of each analyte, except for BDE 209, which was spiked at $0.5 \mathrm{ng} / \mathrm{g}$ ). The recoveries of all PBDE congeners ranged from $81 \%$ to $105 \%$. The lab has been successfully participating in International Intel-calibration sponsored by AMAP (Arctic Monitoring and Assessment Program), organized by Quebec National Institute of Public Health, Canada (AMAP Ring Test for PCBs, Organochlorine Pesticides and PBDEs in Plasma). The relative percent difference (\%RPD) between the laboratory results and the assigned values were $<20 \%$ for all PBDE congeners, except PBDE 209, which was higher (36\%).

Serum total cholesterol and triglycerides were measured enzymatically by the Clinical Laboratory at Children's Hospital (Boston, MA), and total lipids were calculated by Phillips formula (Phillips et al., 1989). It is important to note that the original larger study was designed for analysis of PCBs and IVF outcomes, and therefore there were no precautions taken to prevent PBDE contamination. As a result, there were background concentrations of PBDEs in procedural blanks associated with the samples. The concentrations in blanks were as follows: $0.003+/-0.005 \mathrm{ng} / \mathrm{g}$ for BDE 28, 100, 153, 154 and 183; $0.027+/-0.008 \mathrm{ng} / \mathrm{g}$ for BDE 47; 0.024 +/- $0.008 \mathrm{ng} / \mathrm{g}$ for BDE 99; and 0.057 +/- 0.019 ng/g for BDE 209.

\subsection{Data analysis}

Data analysis was conducted using SAS software version 9.1 (SAS Institute Inc., Cary, NC). In samples where PBDE concentrations were below the detection limit but a signal was detected, the concentration estimated by the GC-MS was used in the data analysis. If no signal was detected for a given sample, then a zero concentration was assigned. Calculations involving serum are based on wet weights for consistency with the follicular fluid measurements, although models of failed implantation were also calculated using lipidadjusted serum. Selected percentiles of PBDE congeners in serum and follicular fluid were 
tabulated. Kendall's Tau-beta correlation coefficients were calculated to assess the level of agreement between paired serum and follicular fluid PBDE concentrations, and between different PBDE congeners within the same matrix. The ratio of PBDE concentrations in follicular fluid to serum was calculated for each congener in all women who had detectable concentrations in both specimens. Logistic regression, adjusted for age and body mass index (BMI), was used to model the odds of failed embryo implantation associated with concentrations of PBDEs. Other variables that were tested in models for potential confounding include race, cigarette smoking and serum levels of PCBs. This analysis restricted the comparison group to live births, and excluded cases of biochemical pregnancies (positive human chorionic gonadotropin test that did not result in a clinical pregnancy), miscarriages, and ectopic pregnancies to provide a purer comparison and due to low numbers of these endpoints.

\section{Results}

Table 1 provides details of the study population, including IVF outcomes. The mean (SD) age among the women was 36 (3.8) years, and ranged from 27 to 44 years. The mean (SD) BMI was 24(4.4), and ranged from 17 to 43 . Most women were Caucasian (84\%) and never smoked (53\%), and very few women were current smokers (6\%). There were $35(55 \%)$ implantation failures and $18(28 \%)$ live births, for a total sample size of 53 for the logistic regression models for failed implantation.

Table 2 presents the distributions and detection rates of PBDE congeners measured in serum and follicular fluid. Lipid-adjusted serum PBDE concentrations are also presented for comparison. In both serum and follicular fluid, BDE 47 had the highest detection rate and mean concentration. Due to relatively high background contamination levels of some PBDE congeners, detection limits are high (0.007-0.112 ng/g), particularly for BDE 209. None of the serum or follicular fluid samples contained BDE 209 above the detection limit. PBDE congeners 47, 99 and 100, main components of the pentaBDE commercial formulation, were correlated with each other within both matrices (Kendall's $\mathrm{T}_{\mathrm{B}}=0.51-0.69, \mathrm{p}<0.0001$, data not shown). BDE 28, which is present in small amounts in the pentaBDE formulation, showed inconsistent rank correlations with the main pentaBDE congeners in serum $\left(\mathrm{T}_{\mathrm{B}}\right.$ $=0.02-0.27, \mathrm{p}=0.004-0.8)$, but were more strongly correlated with the main pentaBDE congeners in follicular fluid $\left(\mathrm{T}_{\mathrm{B}}=0.48-0.57, \mathrm{p}<0.0001\right.$, data not shown). $\mathrm{BDE} 153$, which is present in both the pentaBDE and octaBDE formulations, was also moderately correlated with the main pentaBDE congeners in both matrices $\left(T_{B}=0.26-0.35, \mathrm{p}<0.01\right.$, data not shown). BDE 154, also present in both commercial formulations, was moderately correlated with BDE 100 in serum $\left(T_{B}=0.21, p=0.02\right)$, but more strongly correlated with the main pentaBDE congeners in follicular fluid $\left(\mathrm{T}_{\mathrm{B}}=0.35-0.52, \mathrm{p}<0.001\right.$, data not shown). Table 3 presents the Kendall's Tau-beta correlations between PBDE concentrations in serum and follicular fluid. There were moderate rank correlations between serum and follicular fluid concentrations of $\mathrm{BDE} 28,47,100$ and $154\left(\mathrm{~T}_{\mathrm{B}}=0.29-0.38, \mathrm{p}<0.005\right)$, but $\mathrm{BDE} 99$ and 153 were not correlated between the two matrices $\left(\mathrm{T}_{\mathrm{B}}<0.2, \mathrm{p}>0.05\right)$. Relationships with BDE 183 and BDE 209 were not evaluated due to lower detection rates (serum or follicular fluid detection rate below $25 \%$ ).

The distributions of the ratios of follicular fluid to serum PBDE concentrations are presented in Table 4. Concentrations of PBDEs in follicular fluid were usually lower than PBDE concentrations in serum, although there were several exceptions for all congeners.

Additionally, there were notably two outliers where the follicular fluid PBDE concentrations were much higher than the serum concentration for all congeners. There was also a high level of inter-person variability in the ratios for most of the congeners. 
Odds ratios calculated from logistic regression models of failed embryo implantation corresponding to all PBDE congeners in follicular fluid and serum are presented in Table 5. Women with detectable concentrations of BDE 153 in follicular fluid (39\% of samples) had significantly elevated odds of failed implantation compared with women who had nondetectable BDE 153 concentrations in crude models and when adjusting for age and body mass index (adjusted OR $=10.0 ; 95 \%$ CI: 1.9 to $52 ; \mathrm{p}=0.006$ ). There was also evidence for a dose-response trend when women with detectable BDE 153 concentrations in follicular fluid were divided into equal groups (adjusted OR for non-detect, medium, and high BDE 153 groups $=1.0$ [reference], 6.7, and 18.7, respectively; p-value for trend $=0.008$ ). Age and BMI were included in the models because both variables may be associated with both PBDE exposure and fertility outcomes. Models used wet weight serum and follicular fluid concentrations of PBDEs, and similar results were found when using lipid-adjusted serum (not shown). The inclusion of ethnicity or smoking status (having ever been a smoker) did not change the model estimates by more than 10 percent and were not included in the final models. Because serum concentrations of polychlorinated biphenyls (PCBs) were found to affect implantation in the main study of IVF outcome predictors (Meeker et al., 2011), we also tested models when additionally adjusting for PCB concentrations. The inclusion of PCB concentrations did not change the model estimates by more than 10 percent. Additionally, there was no correlation found between PCB and PBDE concentrations in serum or follicular fluid. Therefore, PCB concentrations were not included in the final models.

\section{Discussion}

To our knowledge this is the first report of PBDE measurement in human follicular fluid. We found increased odds (10-fold) of failed embryo implantation associated with elevated levels of BDE 153 in follicular fluid in a group of women undergoing IVF. Our ability to detect statistically significant associations between other PBDE congeners, in follicular fluid or serum, and failed implantation was limited by relatively high detection limits and a small sample size. Our finding of BDE 153 as the congener with the most influence over implantation may be consistent with the findings in the study by Harley et al. (2010), where BDE 153 was associated with the largest decrease in fecund ability odds ratios as compared to BDE 47, 99 and 100. The Harley et al. study (2010) reported that all four of these PBDE congeners were associated with longer time to pregnancy, as assessed by serum PBDE concentrations and interviews of 223 pregnant women.

The PBDE congeners found at the highest concentrations in serum and follicular fluid were BDE 47, 99, 100, 153 and 154. Similarly, in a large US study of human serum, BDE 47, 99, 100 and 153, main components of the pentaBDE commercial mixture, were the congeners found at the highest concentrations (Sjodin et al., 2008b). Because only moderate correlations were observed between PBDE concentrations in serum and follicular fluid, serum concentrations may not be a good indicator of follicular fluid concentrations when studying fertility and early pregnancy loss in women undergoing IVF. However, our ability to determine a relationship between serum and follicular fluid PBDEs may be hindered by our low detection rates of PBDEs.

The ratios of follicular fluid to serum PBDE concentrations were highly variable between participants. This finding suggests inter-individual differences in exposure or distribution among the women, and that some women may be potentially more susceptible to PBDEs reaching developing follicles. In a previous study (Meeker et al., 2009b) of PCBs in this same population, ratios of follicular fluid PCB concentrations to serum PCB concentrations were less variable $\left(10^{\text {th }}\right.$ percentile $=0.2 ; 90^{\text {th }}$ percentile $\left.=0.4\right)$ than the PBDE ratios in the present study, which led the authors to conclude that serum measurements of PCBs were 
reliable measures of exposure to the oocyte. In the present study there were two individual women whose follicular fluid to serum PBDE ratios were high outliers because their follicular fluid PBDE concentrations were consistently higher than their serum concentrations for all the congeners measured. It is possible that these two follicular fluid samples were contaminated. However, relationships between serum and follicular fluid PBDE concentrations did not improve (correlation coefficients changed by less than 5\% for most congeners and less than $10 \%$ for all congeners) when omitting these outliers. Additionally, the odds ratio of failed implantation for BDE 153 in follicular fluid slightly increased when omitting the two outliers.

The disruption of thyroid hormone homeostasis is a possible mechanism by which PBDEs may influence implantation and fertility. For example, PBDE metabolites may displace T4 from binding to transthyretin, the thyroid transport protein (Meerts et al., 2000). Thyroid hormone disruption may play a role in altered follicle formation, as could disruption along the hypothalamic-pituitary-ovarian axis (Talsness, 2008). For example, several PBDE congeners were found to activate estrogen receptors in-vitro, and PBDE metabolites were especially potent (Meerts et al., 2001). This same study found that several PBDE congeners, including BDE 153, had antiestrogenic effects. Uterine levels of estrogen and progesterone receptor mRNA were also affected by PBDE exposure, although only BDE 99 was tested (Ceccatelli et al., 2006). Talsness et al. (2005) suggested that disrupted mitochondrial regulation by PBDEs may result in the uncontrolled synthesis of steroid products, subsequent vaginal and uterine abnormalities, and increased resorption rates they reported in rats exposed to BDE 99.

Past studies have assessed PBDE exposure to the developing fetus by measuring PBDE concentrations in human placental tissue (Doucet et al., 2009; Main et al., 2007; Miller et al., 2009). However, to our knowledge, this is the first study to report PBDE concentrations in human follicular fluid and to examine the effects of preconception PBDE exposures on early pregnancy. This study was conducted among a group of women undergoing IVF and may be part of a population more sensitive to factors affecting infertility. Thus, the generalizability of our findings remains unclear. However, PBDE exposures as measured in serum in this group of women are representative of the general population (Sjodin A et al., 2008b), and no evidence exists to date to suggest that these women are more susceptible to potential toxic effects of PBDE exposure than women conceiving naturally. Additionally, an advantage of studying IVF populations is the ability to examine sensitive endpoints that would be very difficult or impossible to study in the general population. In their study on PBDE exposure and reduced fecund ability, Harley et al. (2010) point out that, because they studied women who successfully conceived a child naturally, infertile and subfertile women were underrepresented in their study, and PBDE exposure may have an even stronger effect on fertility than they reported. Implantation failure, which is a common occurrence even among women conceiving naturally (Chard, 1991; Norwitz et al., 2001), occurs prior to the detection of pregnancy, and therefore was not measurable in the pregnant population of women studied by Harley et al. (2010). However, implantation failure may be related to the decreased fecund ability found in this population. For this reason, we expect that the study of early pregnancy outcomes, such as the present study of this IVF population, will be useful in elucidating relationships between environmental exposures and fertility for all couples, including those attempting to conceive naturally.

\section{Conclusion}

We found that PBDEs are detectable in follicular fluid and that levels of BDE 153 in follicular fluid may be associated with failed embryo implantation. Our findings may help explain the previous report of a relationship between PBDE exposure and time to pregnancy, 
as failed implantation may manifest as reduced fertility and increased time to pregnancy among women attempting to conceive naturally. Further research with a larger sample size would be needed to confirm the findings of this pilot study.

\section{Highlights}

We compare serum and ovarian follicular fluid as biomarkers of exposure to PBDEs.

We explore the relationship between PBDE exposure and early pregnancy loss.

A strong correlation between PBDEs in the two matrices was not observed.

Exposure to BDE 153 was associated with elevated odds of failed embryo implantation.

\section{Acknowledgments}

This work was supported by grants R01ES013967, R01ES018872, and P30ES017885 from the National Institute of Environmental Health Sciences and grant R01-HD32153 from the National Institute of Child Health and Human Development.

\section{References}

Bloom M, Spliethoff H, Vena J, Shaver S, Addink R, Eadon G. Environmental exposure to PBDEs and thyroid function among New York anglers. Environ Toxicol Pharmacol. 2008; 25:386-392. [PubMed: 21783878]

California Department of Consumer Affairs. [accessed 22 November 2011] State of California Department of Consumer Affairs Bureau of Home Furnishings and Thermal Insulation. Technical Bulletin 117. Requirements, test procedure and apparatus for testing the flame retardance of resilient filling materials used in upholstered furniture. 2000. http://www.bhfti.ca.gov/industry/ 117.pdf

Ceccatelli R, Faass O, Schlumpf M, Lichtensteiger W. Gene expression and estrogen sensitivity in rat uterus after developmental exposure to the polybrominated diphenyl ether PBDE 99 and PCB. Toxicology. 2006; 220:104-116. [PubMed: 16414171]

Chao H, Wang S, Lee W, Wang Y, Papke O. Levels of polybrominated diphenyl ethers (PBDEs) in breast milk from central Taiwan and their relation to infant birth outcome and maternal menstruation effects. Environ Int. 2007; 33:239-245. [PubMed: 17079016]

Chard T. Frequency of implantation and early pregnancy loss in natural cycles. Baillieres Clin Obstet Gynaecol. 1991; 5:179-189. [PubMed: 1855339]

Chevrier J, Harley K, Bradman A, Gharbi M, Sjodin A, Eskenazi B. Polybrominated diphenyl ether (PBDE) flame retardants and thyroid hormone during pregnancy. Environ Health Perspect. 2010; 118:1444-1449. [PubMed: 20562054]

Cramer DW, Sluss PM, Powers RD, McShane P, Ginsburgs ES, Hornstein MD, Vitonis AF, Barbieri RL. Serum prolactin and TSH in an in vitro fertilization population: is there a link between fertilization and thyroid function? J Assist Reprod Genet. 2003; 20:210-215. [PubMed: 12877251]

Dallaire R, Dewailly E, Pereg D, Dery S, Ayotte P. Thyroid function and plasma concentrations of polyhalogenated compounds in Inuit adults. Environ Health Perspect. 2009; 117(9):1380-1386. [PubMed: 19750101]

Doucet J, Tague B, Arnold DL, Cooke GM, Hayward S, Goodyer CG. Persistent organic pollutant residues in human fetal liver and placenta from greater Montreal, Quebec: A longitudinal study from 1998 through 2006. Environ Health Perspect. 2009; 117:605-610. [PubMed: 19440500]

Ellis-Hutchings RG, Cherr GN, Hanna LA, Keen CL. Polybrominated diphenyl ether (PBDE)-induced alterations in vitamin A and thyroid hormone concentrations in the rat during lactation and early postnatal development. Toxicol Appl Pharmacol. 2006; 215:135-145. [PubMed: 16580039] 
EPA (Environmental Protection Agency). [accessed 12 May 2011] Polybrominated Diphenyl Ethers (PBDEs) Action Plan. 2009. http://www.epa.gov/oppt/existingchemicals/pubs/actionplans/ pbde.html

Fowles JR, Fairbrother A, Baecher-Steppan L, Kerkvliet NI. Immunologic and endocrine effects of the flame-retaraant pentabromodiphenyl ether (DE-71) in C57BL/6J mice. Toxicology. 1994; 86:4961. [PubMed: 8134923]

Hagmar L, Bjork J, Sjodin A, Bergman A, Erfurth EM. Plasma levels of persistent organohalogens and hormone levels in adult male humans. Arch Environ Health. 2001; 56:138-143. [PubMed: 11339677]

Hallgren S, Sinjari T, Håkansson H, Darnerud PO. Effects of polybrominated diphenyl ethers (PBDEs) and polychlorinated biphenyls (PCBs) on thyroid hormone and vitamin A levels in rats and mice. Arch Toxicol. 2001; 75:200-208. [PubMed: 11482517]

Hardy ML, Schroeder J, Biesemeier J, Manor O. Prenatal oral (gavage) developmental toxicity study of decabromodiphenyl oxide in rats. Int J Toxicol. 2002; 21:83-91. [PubMed: 12022634]

Harley KG, Marks AR, Chevrier J, Bradman A, Sjödin A, Eskenazi B. PBDE concentrations in women's serum and fecundability. Environ Health Perspect. 2010; 118:699-704. [PubMed: 20103495]

Hites RA. Polybrominated diphenyl ethers in the environment and in people: a meta-analysis of concentrations. Environ Sci Technol. 2004; 38:945-956. [PubMed: 14998004]

Johnson PI, Stapleton HM, Sjodin A, Meeker JD. Relationships between polybrominated diphenyl ether concentrations in house dust and serum. Environ Sci Technol. 2010; 44:5627-5632. [PubMed: 20521814]

Johnson-Restrepo B, Kannan K. An assessment of sources and pathways of human exposure to polybrominated diphenyl ethers in the United States. Chemosphere. 2009; 76:542. [PubMed: 19349061]

Karpeta A, Gregoraszczuk E. Mixture of dominant PBDE congeners (BDE-47, -99, -100 and -209) at levels noted in human blood dramatically enhances progesterone secretion by ovarian follicles. Endocr Regul. 2010; 44:49-55. [PubMed: 20429633]

Kim TH, Lee YJ, Lee E, Kim MS, Kwack SJ, Kim KB, Chung KK, Kang TS, Han SY, Lee J, Lee BM, Kim HS. Effects of gestational exposure to decabromodiphenyl ether on reproductive parameters, thyroid hormone levels, and neuronal development in Sprague-Dawley rats offspring. J Toxicol Environ Health Part A. 2009; 72:1296-1303. [PubMed: 20077200]

Krassas GE, Poppe K, Glinoer D. Thyroid function and human reproductive health. Endocr Rev. 2010; 31:702-755. [PubMed: 20573783]

Lilienthal H, Hack A, Roth-Harer A, Grande SW, Talsness CE. Effects of developmental exposure to 2,2,4,4,5-pentabromodiphenyl ether (PBDE-99) on sex steroids, sexual development, and sexually dimorphic behavior in rats. Environ Health Perspect. 2006; 114:194-201. [PubMed: 16451854]

Lorber M. Exposure of Americans to polybrominated diphenyl ethers. J Expo Sci Environ Epidemiol. 2008; 18:2-19. [PubMed: 17426733]

Main KM, Kiviranta H, Virtanen HE, Sundqvist E, Tuomisto JT, Tuomisto J, Vartiainen T, Skakkebaek NE, Toppari J. Flame retardants in placenta and breast milk and cryptorchidism in newborn boys. Environ Health Perspect. 2007; 115:1519-1526. [PubMed: 17938745]

Meeker JD, Johnson PI, Camann D, Hauser R. Polybrominated diphenyl ether (PBDE) concentrations in house dust are related to hormone levels in men. Sci Total Environ. 2009a; 407:3425-3429. [PubMed: 19211133]

Meeker JD, Maity A, Missmer SA, Williams PL, Mahalingaiah S, Ehrlich S, Berry KF, Altshul L, Perry MJ, Cramer DW, Hauser R. Serum concentrations of polychlorinated biphenyls (PCBs) in relation to in vitro fertilization (IVF) outcomes. Environ Health Perspect. 2011; 119:1010-1016. [PubMed: 21345762]

Meeker JD, Missmer SA, Altshul L, Vitonis AF, Ryan L, Cramer DW, Hauser R. Serum and follicular fluid organochlorine concentrations among women undergoing assisted reproduction technologies. Environ Health. 2009b; 8:32. [PubMed: 19594949] 
Meeker JD, Missmer SA, Cramer DW, Hauser R. Maternal exposure to second-hand tobacco smoke and pregnancy outcome among couples undergoing assisted reproduction. Hum Reprod. 2007a; 22:337-345. [PubMed: 17053002]

Meeker JD, Missmer SA, Vitonis AF, Cramer DW, Hauser R. Risk of spontaneous abortion in women with childhood exposure to parental cigarette smoke. Am J Epidemiol. 2007b; 166:571-575. [PubMed: 17566062]

Meerts IATM, Letcher RJ, Hoving S, Marsh G, Bergman A, Lemmen JG, van der Burg B, Brouwer A. In vitro estrogenicity of polybrominated diphenyl ethers, hydroxylated PBDEs, and polybrominated bisphenol A compounds. Environ Health Perspect. 2001; 109:399-407. [PubMed: 11335189]

Meerts IATM, van Zanden JJ, Luijks EAC, van Leeuwen-Bol I, Marsh G, Jakobsson E, Bergman A, Brouwer A. Potent competitive interactions of some brominated flame retardants and related compounds with human transthyretin in vitro. Tox Sci. 2000; 56:95-104.

Miller M, Chernyak S, Batterman S, Loch-Caruso R. Polybrominated diphenyl ethers in human gestational membranes from women in southeast Michigan. Environ Sci Technol. 2009; 43:30423046. [PubMed: 19534111]

Norwitz ER, Schust DJ, Fisher SJ. Implantation and the survival of early pregnancy. N Engl J Med. 2001; 345:1400-1408. [PubMed: 11794174]

Phillips DL, Pirkle JL, Burse VW, Bernert JT Jr, Henderson LO, Needham LL. Chlorinated hydrocarbon levels in human serum: effects of fasting and feeding. Arch Environ Contam Toxicol. 1989; 18:495-500. [PubMed: 2505694]

Rice DC, Reeve EA, Herlihy A, Zoeller RT, Thompson WD, Markowski VP. Developmental delays and locomotor activity in the C57BL6/J mouse following neonatal exposure to the fullybrominated PBDE, decabromodiphenyl ether. Neurotoxicol Teratol. 2007; 29(4):511-520. [PubMed: 17482428]

Sjödin A, Päpke O, McGahee E, Focant J, Jones RS, Pless-Mulloli T, Toms LM, Herrmann T, Muller J, Needham LL, Patterson DG Jr. Concentration of polybrominated diphenyl ethers (PBDEs) in household dust from various countries. Chemosphere. 2008a; 73:S131-S136. [PubMed: 18501952]

Sjodin A, Wong L, Jones RS, Park A, Zhang Y, Hodge C, Dipietro E, McClure C, Turner W, Needham LL, Patterson DG Jr. Serum concentrations of polybrominated diphenyl ethers (PBDEs) and polybrominated biphenyl (PBB) in the United States population: 2003-2004. Environ Sci Technol. 2008b; 42(4):1377-1384. [PubMed: 18351120]

Skarman E, Darnerud PO, Ohrvik H, Oskarsson A. Reduced thyroxine levels in mice perinatally exposed to polybrominated diphenyl ethers. Environ Toxicol Pharmacol. 2005; 19:273-281. [PubMed: 21783486]

Stapleton HM, Dodder NG, Offenberg JH, Schantz MM, Wise SA. Polybrominated diphenyl ethers in house dust and clothes dryer lint. Environ Sci Technol. 2005; 39:925-931. [PubMed: 15773463]

Stoker TE, Laws SC, Crofton KM, Hedge JM, Ferrell JM, Cooper RL. Assessment of DE-71, a commercial polybrominated diphenyl ether (PBDE) mixture, in the EDSP male and female pubertal protocols. Toxicol Sci. 2004; 78:144-155. [PubMed: 14999130]

Talsness CE. Overview of toxicological aspects of polybrominated diphenyl ethers: A flame-retardant additive in several consumer products. Environ Res. 2008; 108:158-167. [PubMed: 18949835]

Talsness CE, Kuriyama SN, Sterner-Kock A, Schnitker P, Grande SW, Shakibaei M, Andrade A, Grote K, Chahoud I. In utero and lactational exposures to low doses of polybrominated diphenyl ether-47 alter the reproductive system and thyroid gland of female rat offspring. Environ Health Perspect. 2008; 116:308-314. [PubMed: 18335096]

Talsness CE, Shakibaei M, Kuriyama SN, Grande SW, Sterner-Kock A, Schnitker P, de Souza C, Grote K, Chahoud I. Ultrastructural changes observed in rat ovaries following in utero and lactational exposure to low doses of a polybrominated flame retardant. Toxicol Lett. 2005; 157:189-202. [PubMed: 15917144]

Turyk ME, Persky VW, Imm P, Knobeloch L, Chatterton R Jr, Anderson HA. Hormone disruption in adult male sport fish consumers. Environ Health Perspect. 2008; 116:1635-1641. [PubMed: 19079713] 
Wang H, Zhang Y, Liu Q, Wang F, Nie J, Qian Y. Examining the relationship between brominated flame retardants (BFR) exposure and changes of thyroid hormone levels around e-waste dismantling sites. Int J Hyg Environ Health. 2010; 213:369-380. [PubMed: 20598942]

Wu N, Herrmann T, Papke O, Tickner J, Hale R, Harvey E, La Guardia M, McClean MD, Webster TF. Human exposure to PBDEs: associations of PBDE body burdens with food consumption and house dust concentrations. Environ Sci Technol. 2007; 41:1584-1588. [PubMed: 17396645]

Yuan J, Chen L, Chen D, Guo H, Bi X, Ju Y, Jiang P, Shi J, Yu Z, Yang J, Li L, Jiang Q, Sheng G, Fu $\mathrm{J}$, Wu T, Chen X. Elevated serum polybrominated diphenyl ethers and thyroid-stimulating hormone associated with lymphocytic micronuclei in Chinese workers from an e-waste dismantling site. Environ Sci Technol. 2008; 42:2195-2200. [PubMed: 18411489]

Zhou T, Ross DG, DeVito MJ, Crofton KM. Effects of short-term in vivo exposure to polybrominated diphenyl ethers on thyroid hormones and hepatic enzyme activities in weanling rats. Toxicol Sci. 2001; 61:76-82. [PubMed: 11294977]

Zhou T, Taylor MM, DeVito MJ, Crofton KM. Developmental exposure to brominated diphenyl ethers results in thyroid hormone disruption. Toxicol Sci. 2002; 66:105-116. [PubMed: 11861977]

Zoeller, RT.; Meeker, JD. The thyroid system. In: Woodruff, TJ.; Janssen, SJ.; Guillette, LJ.; Giudice, LC., editors. Environmental Impacts on Reproductive Health and Fertility. New York: Cambridge University Press; 2010. p. 180-187. 


\section{Table 1}

Characteristics of study population

\begin{tabular}{lrr}
\hline Age, yrs. [median (min,max)] & $38(27,44)$ \\
Body mass index [median (min,max)] & $23(17,43)$ \\
Caucasian & $\mathbf{n}$ & $(\%)$ \\
Other/unspecified & 54 & 84 \\
never smoked & 11 & 16 \\
past smoker & & \\
current smoker & 34 & 53 \\
Smoking status & 30 & 47 \\
IVF Outcomes & 4 & 6.3 \\
Implantation failure & & \\
Live birth & 35 & 55 \\
Chemical pregnancy only & 18 & 28 \\
Miscarriage & 6 & 9.4 \\
Ectopic pregnancy & 3 & 4.7 \\
\hline
\end{tabular}




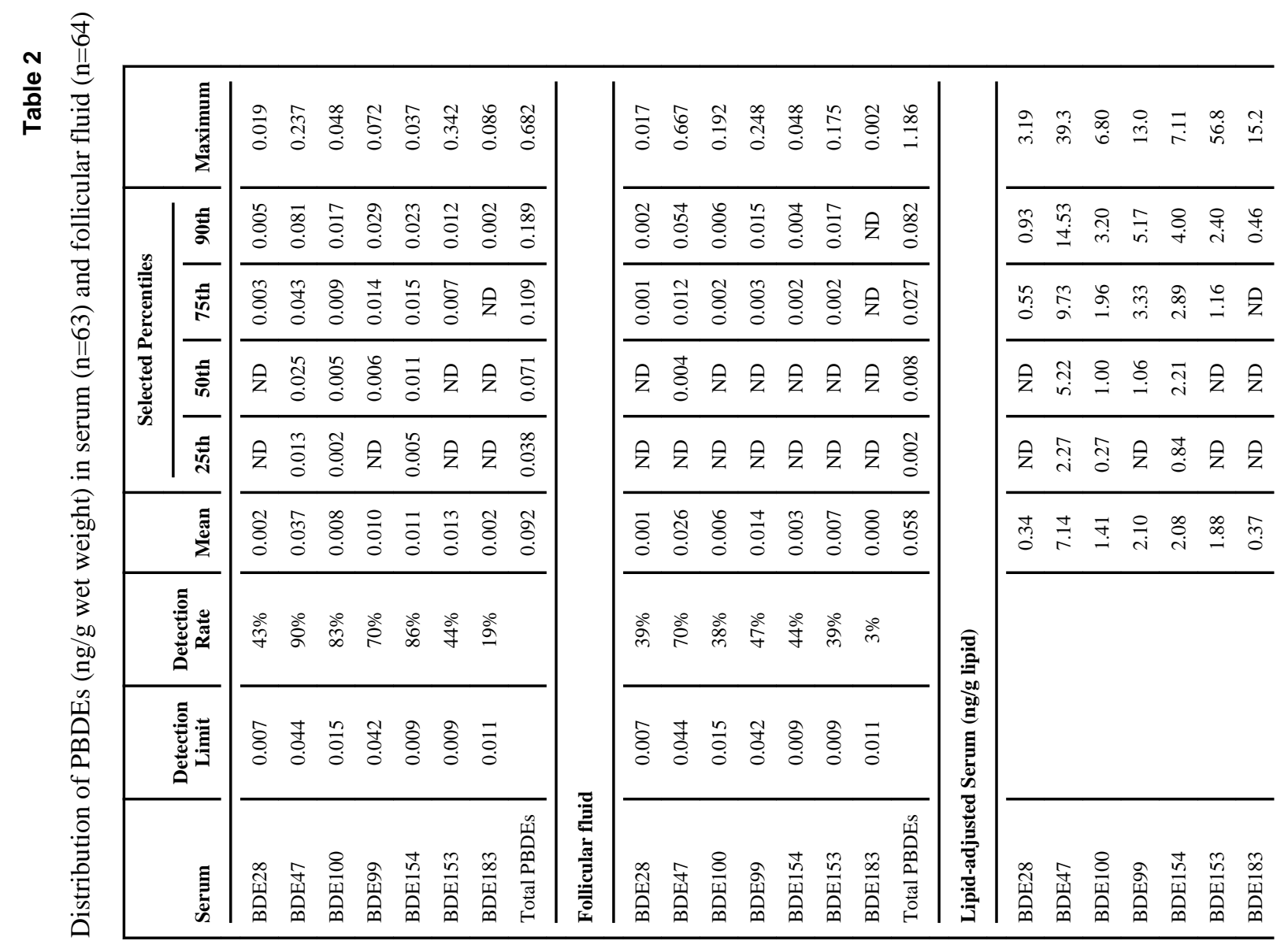






Page 14 
Table 3

Kendall's Tau-beta correlation coefficients for PBDE concentrations in serum and follicular fluid ( $\mathrm{n}=62$ )

\begin{tabular}{|l|c|c|}
\hline & $\mathbf{T}_{\mathbf{B}}$ & p-value \\
\hline BDE 28 & 0.33 & 0.002 \\
\hline BDE 47 & 0.38 & $<0.0001$ \\
\hline BDE 100 & 0.36 & 0.0003 \\
\hline BDE 99 & 0.11 & 0.26 \\
\hline BDE 154 & 0.29 & 0.003 \\
\hline BDE 153 & 0.15 & 0.16 \\
\hline
\end{tabular}


Table 5

Odds ratios for implantation failure associated with elevated (above median, or, if $<50 \%$ detected, detectable) levels in serum or follicular fluid $(n=53)$

\begin{tabular}{|r|c|c|}
\hline Serum & $\begin{array}{c}\text { Crude OR } \\
(\mathbf{9 5 \%} \text { CI) }\end{array}$ & $\begin{array}{c}\text { Adjusted }^{\boldsymbol{a}} \text { OR } \\
\mathbf{( 9 5 \%} \text { CI) }\end{array}$ \\
\hline BDE 28 & $1.2(0.4,3.8)$ & $1.2(0.4,3.9)$ \\
BDE 47 & $1.5(0.5,4.7)$ & $1.6(0.5,5.4)$ \\
BDE 100 & $1.5(0.5,4.7)$ & $1.5(0.5,4.9)$ \\
BDE 99 & $1.5(0.5,4.7)$ & $1.7(0.5,5.6)$ \\
BDE 154 & $2.8(0.8,9.4)$ & $3.0(0.8,10)$ \\
BDE 153 & $1.0(0.3,3.4)$ & $1.2(0.3,4.4)$ \\
Total PBDEs & $1.2(0.4,3.7)$ & $1.2(0.4,4.0)$ \\
\hline Follicular Fluid & \\
\hline BDE 28 & $1.2(0.4,3.8)$ & $1.2(0.4,4.0)$ \\
BDE 47 & $0.8(0.3,2.7)$ & $0.9(0.3,2.7)$ \\
BDE 100 & $0.7(0.2,2.3)$ & $0.7(0.2,2.5)$ \\
BDE 99 & $0.4(0.1,1.4)$ & $0.4(0.1,1.4)$ \\
BDE 154 & $1.9(0.6,6.2)$ & $2.1(0.6,7.4)$ \\
BDE 153 & $5.9(1.5,24)$ & $10(1.9,51)$ \\
Total PBDEs & $1.7(0.5,5.2)$ & $1.8(0.5,6.0)$ \\
\hline
\end{tabular}

${ }^{a}$ Adjusted by age and BMI 